\title{
Tumour necrosis factor $\alpha$ inhibitor treatment for sarcoidosis refractory to conventional treatments: a report of five patients
}

\author{
C Pritchard, K Nadarajah
}

Ann Rheum Dis 2004;63:318-320. doi: 10.1136/ard.2002.004226

Objective: To study the effectiveness of tumour necrosis factor $\alpha(T N F \alpha)$ inhibitor treatment for sarcoidosis refractory to conventional treatments.

Methods: Five patients (two men, three women) were treated with infliximab. All patients received a loading dose of $3 \mathrm{mg} / \mathrm{kg}$ at 0,2 , and 6 weeks and then maintenance infusions every 4-8 weeks. Patients had their dose increased or the dosing interval reduced when the disease relapsed. These patients had active disease despite treatment with corticosteroids and other immunomodulatory agents. All patients had a negative tuberculin skin test.

Results: Sarcoidosis in all patients improved significantly without any serious adverse reactions.

Conclusion: This study suggests that TNF $\alpha$ is effective in patients for whom conventional treatment fails.

S arcoidosis is a multisystem disorder of unknown aetiology. The disease can be self limiting or chronic with episodes of remission and relapse. Its classic pathological feature is non-caseating granuloma. Many studies have shown high tumour necrosis factor $\alpha$ (TNF $\alpha)$ production in sarcoidosis ${ }^{2}$ and the role of $\mathrm{TNF} \alpha$ in granuloma development. Granuloma is an antigen mediated process, regulated by CD4 $\mathrm{T}$ helper cells and the cells derived from the mononuclear phagocyte lineage. ${ }^{3}$ Antigen presenting cells in affected sites produce proinflammatory cytokines such as interleukin (IL) 12. This mediates the release of Thl cells, which express IL2 and interferon gamma. ${ }^{34}$ This cytokine cascade attracts blood monocytes to the affected tissues, where they differentiate into macrophages that release several cytokines including $\mathrm{TNF} \alpha$. TNF $\alpha$ up regulates adhesion molecules such as intracellular adhesion molecule-1, which enhances lymphocyte activation, cell binding, and granuloma formation. ${ }^{4} \mathrm{TNF} \alpha$ also promotes the proliferation of $\mathrm{T}$ lymphocytes and the subsequent release of interferon gamma. ${ }^{4}$

Infliximab is a chimeric monoclonal human mouse antibody against TNF $\alpha$. At present it is approved by the Food and Drug Administration for the management of rheumatoid arthritis and Crohn's disease. We describe five patients with sarcoidosis treated with infliximab. These patients had active disease despite corticosteroid and other immunomodulatory treatments at the time when infliximab was started, and all had negative tuberculin skin tests. Table 1 shows the maximum dosage of drugs tried before infliximab and the approximate duration of treatment when known. Sarcoidosis improved significantly in all patients without any serious adverse reactions.

\section{PATIENTS AND METHODS}

Five patients (two men, three women) were included in the study. All patients had a diagnosis of sarcoidosis by biopsy proven non-caseating granuloma and raised serum angiotensin converting enzyme (ACE) levels.

Patient 1 is a 31 year old Caucasian man with sarcoid uveitis. He had blurring of vision and eye pain, usually one eye at a time, worse in the left eye. He was receiving methotrexate $20 \mathrm{mg}$ weekly when infliximab was started.

Patient 2 is a 74 year old Caucasian woman also with sarcoid uveitis. She was receiving cyclosporin $125 \mathrm{mg}$ daily and methotrexate $7.5 \mathrm{mg}$ weekly. She had recurrent uveitis during treatment with these drugs and needed frequent dose adjustments.

Patient 3 is 37 year old African-American woman with pulmonary sarcoidosis and arthralgias. Chest $x$ ray examination showed bilateral hilar lymphadenopathy, and transbronchial biopsy showed sarcoid granuloma. Her primary symptoms were dyspnoea, arthralgia, and fatigue. She was receiving prednisone $40 \mathrm{mg}$ daily and methotrexate $7.5 \mathrm{mg}$ weekly when infliximab was started.

Patient 4 is a 41 year old African-American man with a distant history of pulmonary sarcoidosis treated with high dose steroid initially and then hydroxychloroquine for 17 years with symptoms in remission. He then developed a burning sensation and numbness in both hands, legs, and over the chest, extending from the umbilicus to the nipples. A month later he had a motor vehicle accident requiring a splenectomy. After this accident his symptoms worsened and he became wheelchair bound. Magnetic resonance imaging (MRI) of his spinal cord showed an abnormal linear signal at the T2 level. After exclusion of other causes he was diagnosed with myelopathy attributed to neurosarcoidosis. He was receiving prednisone $10 \mathrm{mg}$ daily and hydroxychloroquine $400 \mathrm{mg}$ daily when infliximab was started several months after diagnosis of neurosarcoidosis.

Patient 5 is a 32 year old Caucasian woman with a history of several organs affected by sarcoidosis. Her predominant symptoms at the start of infliximab were intermittent episodes of diarrhoea and abdominal pain from colitis, sarcoid skin nodules, vaginal bleeding from sarcoid endometritis, arthralgias, and fatigue. She was receiving methylprednisone $8 \mathrm{mg}$ daily.

\section{RESULTS}

Patient 1 responded to treatment with infliximab after 3 weeks. Eye pain and blurring of vision improved and he

\footnotetext{
Abbreviations: $\mathrm{ACE}$, angiotensin converting enzyme; $\mathrm{CT}$, computed tomography; IL, interleukin; MRI, magnetic resonance imaging; $\mathrm{TNF} \alpha$, tumour necrosis factor $\alpha$
} 
Table 1 Maximum dosage of drugs tried before starting infliximab in patients $1-5$, and approximate duration of treatment when known

\begin{tabular}{|c|c|c|c|c|}
\hline Patient 1 & Patient 2 & Patient 3 & Patient 4 & Patient 5 \\
\hline $\begin{array}{l}\text { Glucocorticoids } \\
\text { Hydroxychloroquine } \\
400 \mathrm{mg} \text { daily } \\
\text { Methotrexate } 20 \mathrm{mg} \\
\text { weekly for } 3 \text { months }\end{array}$ & $\begin{array}{l}\text { Glucocorticoids } \\
\text { Methotrexate } 7.5 \mathrm{mg} \text { weekly } \\
\text { Cyclosporin } 125 \mathrm{mg} \text { daily }\end{array}$ & $\begin{array}{l}\text { Glucocorticoids } \\
\text { Methotrexate } 7.5 \mathrm{mg} \\
\text { weekly for } 3 \text { months }\end{array}$ & $\begin{array}{l}\text { Glucocorticoids } \\
\text { Hydroxychloroquine } \\
400 \text { mg daily } \\
\text { Methotrexate } 10 \mathrm{mg} \\
\text { weekly for } 3 \text { months } \\
\text { Azathioprine } 50 \mathrm{mg} \\
\text { weekly for } 4 \text { months }\end{array}$ & $\begin{array}{l}\text { Glucocorticoids } \\
\text { Hydroxychloroquine } 600 \mathrm{mg} \\
\text { weekly for } 3 \text { years } \\
\text { Methotrexate } 7.5 \mathrm{mg} \text { weekly for } \\
18 \text { months } \\
\text { Cyclosporin } 100 \mathrm{mg} \text { daily for } \\
6 \text { months } \\
\text { Leflunomide } 20 \mathrm{mg} \text { daily for } \\
9 \text { months }\end{array}$ \\
\hline
\end{tabular}

stopped methotrexate on his own without a flare of sarcoidosis. Twelve months later he relapsed. Uveitis was noted to recur 5 weeks after infliximab infusion. Reducing the dosing interval to 4 weeks controlled the symptoms.

Patient 2 had improved 2 weeks after infusion. Her cyclosporin was discontinued and methotrexate was slowly reduced to $2.5 \mathrm{mg}$ every two weeks. Infliximab was continued at 8- weekly intervals.

In patient 3 dyspnoea and arthralgia improved 1-2 months after treatment. A computed tomography (CT) scan of the thorax before and 6 months after infliximab showed improvement in the enlarged hilar lymph nodes. The serum ACE level was $132 \mathrm{U} / \mathrm{l}$ (reference range 8-52) on diagnosis and decreased to $61 \mathrm{U} / \mathrm{l}$ with initial steroid treatment and to $22 \mathrm{U} / \mathrm{l}$ after 8 months of infliximab infusions.

Treatment of patient 4 was started with $3 \mathrm{mg} / \mathrm{kg}$ infliximab every 6 weeks. Two months later he was able to walk without assistive devices. His stiffness, sensory loss, and gait dysfunction improved and he was subsequently able to regain his driving ability. A repeat MRI scan of the thoracic spine showed persistent abnormality at the T2 level. The infliximab dose was increased to $6 \mathrm{mg} / \mathrm{kg}$ and then to $10 \mathrm{mg} / \mathrm{kg}$ as a burning sensation recurred in his feet. Hydroxychloroquine was stopped. Prednisone was reduced to $2.5 \mathrm{mg}$ daily and continues to be tapered with symptoms in remission. He continues to receive this dose of infliximab.

Patient 5 showed a dramatic response. Her skin nodules disappeared after 2 days. All symptoms improved 4 weeks after the first dose. A month later the dose was increased to $6 \mathrm{mg} / \mathrm{kg}$ because of recurrence of sarcoid endometritis and arthralgias. She had further dose change a year later to $10 \mathrm{mg} / \mathrm{kg}$ every four weeks as some symptom relapse occurred about 3 weeks after infusion.

In all patients infliximab was given at $3 \mathrm{mg} / \mathrm{kg}$ at 0,2 , and 6 weeks (similar to the dose used for patients with rheumatoid arthritis). Patients 1, 2, and 3 initially received it 8 weekly. Patients 4 and 5 with neurosarcoidosis and multiorgans affected were given infliximab every 6 and 4 weeks, respectively. Persistence or relapse of disease manifestation was managed by increasing the dose or reducing the dosing interval. A dose-response relationship was noted in the ATTRACT trial with infliximab. ${ }^{5}$ Patients 1 , 2 , and 3 were receiving methotrexate at the start of treatment and this was gradually weaned. It is unclear if combined treatment is beneficial as it is in rheumatoid arthritis.

In patient 3, the serum ACE level decreased after infliximab treatment. Complete data on the serum ACE levels were not available in the other patients. All five patients tolerated the treatment and there were no adverse effects.

\section{DISCUSSION}

Infliximab is a chimeric monoclonal human mouse antibody against TNF $\alpha$. The efficacy of other anti-TNF agents such as pentoxifylline and thalidomide in treating sarcoidosis has shown that TNF $\alpha$ is a key cytokine in the inflammatory cascade seen in sarcoidosis. These agents have been shown in studies to inhibit $\mathrm{TNF} \alpha$ production by human alveolar macrophages. ${ }^{67}$ There have been case reports and small case series of the use of infliximab in refractory sarcoidosis with dramatic improvements. $^{89}$

Three of our patients (patient 1, 2, 5) had chronic granulomatous uveitis. The eye was the primary organ affected in patients 1 and 2. TNF $\alpha$ is an important cytokine in the pathogenesis of ocular inflammation. ${ }^{10}$ Similar observations have been shown in most models. ${ }^{11}{ }^{12}$ One of our patients developed an episode of visual blurring while receiving treatment, but uveitis was not diagnosed. There have been case reports of uveitis in patients receiving treatment with $\mathrm{TNF} \alpha$ inhibitors in other systemic diseases. ${ }^{13}$ $\mathrm{TNF} \alpha$ inhibitors have been used in the management of many systemic disorders associated with eye inflammation-for example, ankylosing spondylitis, Crohn's disease, and rheumatoid arthritis. However, there appears to be a differential efficacy of $\mathrm{TNF} \alpha$ inhibition in treating inflammatory eye diseases associated with systemic disorders. For example, eye inflammation as compared with joint inflammation in the same disease responds differently to $\mathrm{TNF} \alpha$ inhibitors. This may be explained by the requirement for distinct classes of cytokines, lymphocytes, and adhesion molecules for inflammatory reactions at different organ sites. ${ }^{13}$

Patient 4 had neurosarcoidosis. This is an uncommon manifestation of the disease. Intraspinal neurosarcoidosis is even more rare and may present as myelopathy. Steroids have been the preferred treatment. In this patient steroids mildly improved stiffness in the legs, strength, and gait dysfunction. There was a pronounced response in the patient to treatment with infliximab, particularly in his ability to walk without assistive devices and his ability to drive again. However, his MRI abnormality in the thoracic spine persists. A new onset of demyelinating disorders and a case of aseptic meningitis have been documented after infliximab use. ${ }^{14}$ Any new neurological presentation requires treatment to be stopped and investigation of the patient.

Patient 3 had symptoms of pulmonary disease. A repeat CT thorax 9 months after treatment showed improvement in hilar lymphadenopathy. Improvement in the vital capacity and chest $x$ ray findings after infliximab treatment in a patient with stage 3 pulmonary disease have been reported. ${ }^{9}$ Patient 5 in our report had multiple organs affected: eyes, nervous system, lungs, uterus, colon, and skin. Of note, her skin nodules disappeared 2 days after treatment. Two other patients with chronic sarcoid skin changes in a study responded to infliximab. ${ }^{9}$

No serious infection occurred, notably with lack of spleen in one of our patients. One patient had dyspnoea during the first infusion, which was prevented by premedicating with diphenhydramine in the subsequent infusions in this patient. 
Another patient developed tremors of the lower extremities that were benign; it is unclear if these were due to infliximab. This patient did not elect to stop treatment. All patients were screened for latent tuberculous infection before the start of treatment as infliximab has been known to reactivate latent tuberculosis. ${ }^{15}$ Obtaining a history for exposure to tuberculosis is essential as the purified protein derivative skin test may be falsely negative in patients with sarcoidosis owing to anergy.

TNF $\alpha$ inhibitor treatment appears to be useful in the management of chronic resistant sarcoidosis, particularly when other immunomodulatory treatments and steroids have failed. The benefit of this treatment supports the fact that sarcoidosis is a TNF mediated disease. Probably anti-TNF treatment will become standard in the treatment of patients with refractory sarcoidosis.

\section{Authors' affiliations}

C Pritchard, K Nadarajah, Rheumatology Specialty Center, 2400 Maryland Road, Suite 40, Willow Grove, PA 19090, USA

Correspondence to: Dr K Nadarajah; knadarajah@amh.org

Accepted 12 May 2003

\section{REFERENCES}

1 Zheng L, Tescheler H, Guzman J, Hubner K, Striz I, Costabel U. Alveolar macrophage TNF $\alpha$ release and BAL cell phenotypes in sarcoidosis: Am J Respir Crit Care Med 1995;152:1061-6.

2 Steffen M, Petersen J, Oldigs M, Karmeier A, Magnussen H, Thiele HG, et al. Increased secretion of tumor necrosis factor-alpha, interleukin-1-beta, and interleukin- 6 by alveolar macrophages from patients with sarcoidosis: J Allergy Clin Immunol 1993;91:939-49.

3 Moller DR. Cells and cytokines involved in the pathogenesis of sarcoidosis. Sarcoidosis Vasc Diffuse Lung Dis 1999;16:24-31.

4 Barnard J, Newman LS. Sarcoidosis: immunology, rheumatic involvement, and therapeutics. Curr Opin Rheumatol 2001;13:84-91.

5 Maini R, St Clair EW, Breedveld F, Furst D, Kalden J, Weisman M, et al. Infliximab versus placebo in rheumatoid arthritis patients receiving concomitant methotrexate: a randomised phase 3 trial. ATTRACT Study group. Lancet 1999;354:1932-9.

6 Marques L, Zheng L, Poulakis N, Guzman J, Costabel U. Pentoxifylline inhibitsTNF-alpha production from human alveolar macrophages. Am J Respir Crit Care Med 1999;159:508-11.

7 Tavares JL, Wangoo A, Dilworth P, Marshall B, Kotecha S, Shaw RJ. Thalidomide reduces tumour necrosis factor-alpha production by human alveolar macrophages. Respir Med 1997;91:31-9.

8 Yee AM, Pochapin MB. Treatment of complicated sarcoidosis with infliximab anti-tumor necrosis factor-alpha therapy. Ann Intern Med 2001;135:27-31.

9 Baughman RP, Lower EE. Infliximab for refractory sarcoidosis. Sarcoidosis Vasc Diffuse Lung Dis 2001;18:70-4.

10 Lacomba SM, Martin MC, Gallardo Galera JM, Gomez Vidal MA, Estevez CE, Chamond RR, et al. Aqueous humor and serum tumor necrosis factor-alpha in clinical uveitis. Opthalmic Res 2001;33:251-5.

11 de Vos AF, van Haren MA, Verhagen C, Hoekzema R, Kiilstra A. Kinetics of intraocular tumor necrosis factor and interleukin- 6 in endotoxin induced uveitis in the rat. Invest Ohpthalmol Vis Sci 1994;35:1100-6.

12 Smith JR, Hart PH, Coster DJ, Williams KA. Mice deficient in tumor necrosis factor receptors p55 and p75, IL-4, or inducible nitric oxide synthase are susceptible to endotoxin induced uveitis. Invest Ophthalmol Vis Sci 1998;39:658-61.

13 Smith JR, Levinson RD, Holland GN, Jabs DA, Robinson MR, Whitcup SM, ef al. Differential efficacy of tumor necrosis factor inhibition in the management of inflammatory eye disease and associated rheumatic disease. Arthritis Care Res $2001 ; 45: 252-7$.

14 Day R. Adverse reactions to TNF-alpha inhibitors in rheumatoid arthritis. Lancet 2002;359:540-1.

15 Keane J, Gerson S, Wise RP, Mirable-Levens E, Kasznica J, Schwieterman WD, et al. Tuberculosis associated with infliximab, a tumor necrosis factor alpha-neutralizing agent. N Engl J Med 2001;345:1098-104. 